\title{
CHARACTERIZATION OF A MAGNESIUM ALLOY PROCESSED BY HIGH-PRESSURE TORSION ${ }^{1}$
}

\author{
Lívia Raquel Cupertino Malheiros ${ }^{2}$ \\ Roberto Braga Figueiredo ${ }^{3}$ \\ Paulo Roberto Cetlin ${ }^{4}$ \\ Terence G. Langdon ${ }^{5}$
}

\begin{abstract}
The processes of severe plastic deformation are being studied for producing ultrafine-grained structures in metallic materials. Among these processes, HighPressure Torsion, (HPT), is more effective for the grain refinement. The present work aims to observe the effect of pressure variation in the microstructure and the distribution of hardness in samples of AZ31 magnesium processed by HPT. Two disks were processed under pressures of $6.0 \mathrm{GPa}$ and $1.0 \mathrm{GPa}$ to a large number of rotations. The results show the presence of cracks in the sample processed under lower pressure. Also, the microstructure and hardness distribution show heterogeneity in deformation along the longitudinal section.

Key words: High-pressure torsion; Magnesium alloys; Severe plastic deformation.

\section{CARACTERIZAÇÃO DE UMA LIGA DE MAGNÉSIO PROCESSADA POR TORÇÃO SOB ALTA PRESSÃO}

\section{Resumo}

Os processos de deformação plástica severa estão sendo estudados por produzirem estruturas com grãos ultrafinos em materiais metálicos. Entre esses processos, a torsão sob alta pressão, (HPT), é o mais efetivo no refinamento de grãos. O presente trabalho visa observar o efeito da variação da pressão na microestrutura e distribuição de dureza em amostras de magnésio AZ31 processadas por HPT. Dois discos foram processados até elevado número de voltas sob pressões de $6.0 \mathrm{GPa}$ e $1.0 \mathrm{GPa}$. Os resultados mostram a ocorrência de trincas na amostra processada sob a pressão mais baixa. Além disso, a microestrutura e a distribuição de dureza mostraram heterogeneidade na deformação ao longo da secção longitudinal.

Palavras-chave: Torsão sob alta pressão; Magnésio; Deformação plástica severa.

1 Technical contribution to $68^{\text {th }}$ ABM International Congress, July, $30^{\text {th }}$ to August $2^{\text {nd }}, 2012$, Belo Horizonte, MG, Brazil.

2 Undergraduate Student in Metallurgical Engineering. Universidade Federal de Minas Gerais; Belo Horizonte, MG, Brazil

3 Mechanical engineering. Dr. Department of Materials Engineering and Civil Construction, Universidade Federal de Minas Gerais; Belo Horizonte, MG, Brazil

4 Metallurgical engineering. Dr.. Department of Mechanical Engineering, Universidade Federal de Minas Gerais; Belo Horizonte, MG, Brazil

5 Physical metallurgy, Ph.D. Faculty of Engineering and the Environment, University of Southampton, Southampton, U.K. / Departments of Aerospace \& Mechanical Engineering and Materials Science, University of Southern California, Los Angeles, U.S.A. 


\section{INTRODUCTION}

The processes of severe plastic deformation $(\mathrm{SPD})^{(1)}$ have attracted significant attention due to their potential for promoting structure refinement in metallic materials. Ultrafine-grained and even nanostructured materials were produced by SPD techniques. The most common SPD techniques are Equal-Channel Angular Pressing (ECAP) ${ }^{(2)}$ and High-Pressure Torsion (HPT) ${ }^{(3)}$ The former is characterized by the pressing of a sample with prismatic shape through a die containing two intersecting channels with equal cross-section. The latter is characterized by the application of compression stresses on a disc-shaped sample and concurrent torsional straining. The compressive stress state is generated by a compression force between two massive anvils and the torsional strain is generated by the rotation of one of the anvils in relation to the other. Figure 1 illustrates the HPT process. ${ }^{(4)}$ Among the SPD techniques, High Pressure Torsion (HPT) is more effective for producing grain refinement.

The sample used in HPT is usually a thin disc which is subjected to an axial pressure that leads to a compressive stress state in the sample and prevents the appearance of cracks. Theoretically, the effective strain, $\varepsilon$, due to the HPT is given by equation $1:{ }^{(5)}$

$$
\varepsilon=\frac{2 \pi N r}{h \sqrt{3}}
$$

where $r$ is the radial distance from the center, $N$ is the number of turns and $h$ is the disk thickness. In practice, the reduced thickness of the sample allows the imposition of large values of strain at the edge of discs processed by large number of turns.

Many different materials have been processed by HPT including aluminum, ${ }^{(6)}$ copper ${ }^{(7)}$ and iron. ${ }^{(8)} \mathrm{A}$ few papers report the processing of magnesium alloys as well. Samples of AZ61 (Mg- 6\% Al-1\% Zn) alloy were processed by HPT under a pressure of $3 \mathrm{GPa}$ leading to equilibrium grain sizes of $0.22 \mu \mathrm{m}$ at a high temperature (423 K) and $0.11 \mu \mathrm{m}$ at room temperature and up to $110 \mathrm{Hv}$ of hardness. ${ }^{(9)}$ Also, discs of AZ31 (Mg-3\% Al-1\% Zn) alloy were processed by HPT under a pressure of $6.0 \mathrm{GPa}$ for $1 / 4,1$ and 5 turns at room temperature $(296 \mathrm{~K})$ and high temperature (463 K) [10]. Characterization of the structure and hardness distributions along the throughthickness direction of the HPT processed discs showed the deformation is highly heterogeneous. $^{(10)}$

There is a report of heterogeneous hardness distribution along the diameter of a sample processed by HPT to low numbers of turns and a tendency for homogenization at large numbers. ${ }^{(6)}$ Thus, the present paper aims to determine if this trend of homogeneization at larger numbers of turns is also observed in magnesium. The structure and hardness distribution along the through thickness of an AZ31 magnesium alloy processed to larger number of turns of HPT is used to evaluate the tendency for homogenization. 


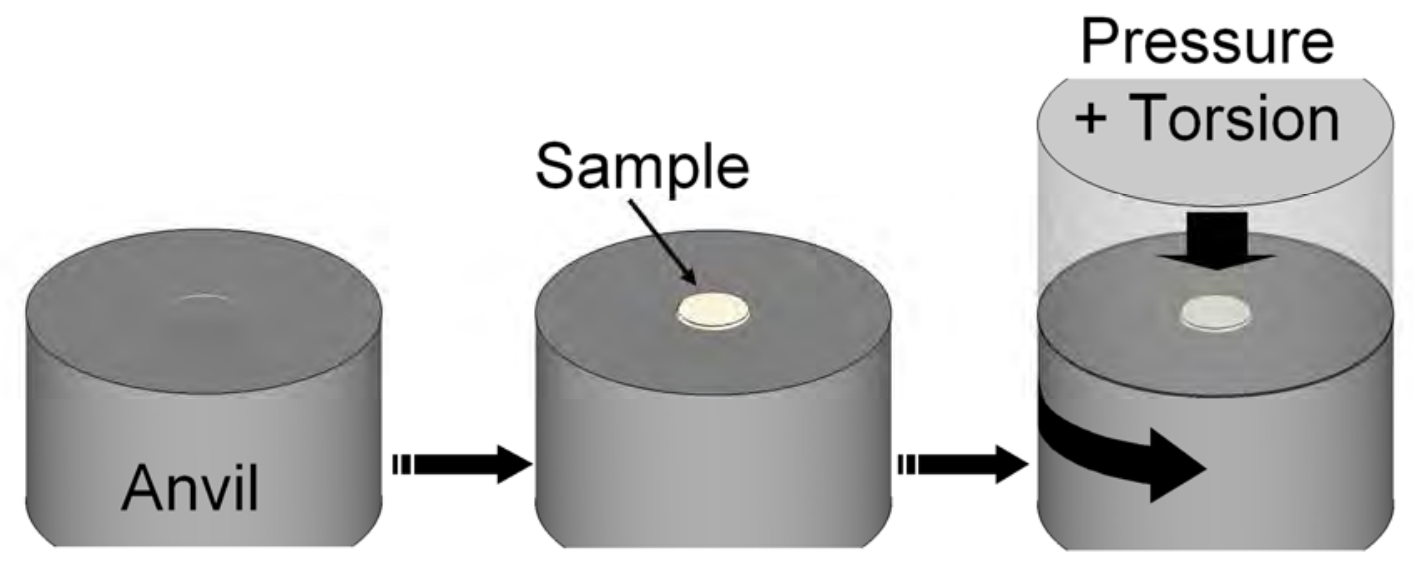

Figure 1: Illustration of high-pressure torsion. ${ }^{(4)}$

\section{EXPERIMENTAL PROCEDURE}

The material used in the experiments was an AZ31 alloy supplied by Timminco Co. (Aurora, CO, USA) in the form of extruded bars with $10 \mathrm{~mm}$ diameter. Discs with $\sim 1.5$ $\mathrm{mm}$ thickness were cut from the bars and ground with abrasive papers up to $\sim 0.8$ $\mathrm{mm}$. These discs were processed by HPT under pressures of 6.0 and $1.0 \mathrm{GPa}$ for $1 / 4,1,5$ and 20 turns at room temperature (296K). After processing, the discs were cut and embedded in resin. The longitudinal plane (containing the radial direction and through-thickness direction) was ground with abrasive papers \#100, 240, 320, 400, 600 and 1000. Final polishing was carried out with alumina suspension ( $3 \mu \mathrm{m}$ and $1 \mu \mathrm{m})$ to produce mirror-like finishes.

The polished surfaces were etched with a solution of $5 \mathrm{ml}$ of nitric acid and $95 \mathrm{ml}$ of ethyl alcohol for $\sim 20 \mathrm{~s}$. The etched surfaces were observed and photographed in an optical microscope. These surfaces were polished again to a mirror-like finish and multiple indentations were made using a Vickers indenter at selected positions. The load used was $50 \mathrm{gf}$ and the dwell time was $15 \mathrm{~s}$. The values of microhardness were used to plot color-coded maps of hardness as a function of the position along the surface.

\section{RESULTS}

Figure 2 shows the longitudinal section of the discs of AZ31 alloy. The disc at the top was processed under a nominal pressure of $1 \mathrm{GPa}$ and the disc at the bottom was processed at $6 \mathrm{GPa}$. A darker area is observed around the center of the discs. There is also observed a clear distinction in color along the sample thickness. In order to observe more clearly the heterogeneous regions of the discs, three specific areas of the samples ( $a, b$ and $c$ ) were photographed at higher magnification.

Figure 3 shows the top left corner of the longitudinal section of the sample processed to 20 turns of HPT using a pressure of $1 \mathrm{GPa}$. This area is highlighted in box (a) in Figure 2. This area is processed near the corner of the top anvil. Dark segments crossing the top corner are clearly visible. The etching pattern differs at opposite sides of these segments which suggests a separation between these areas. 


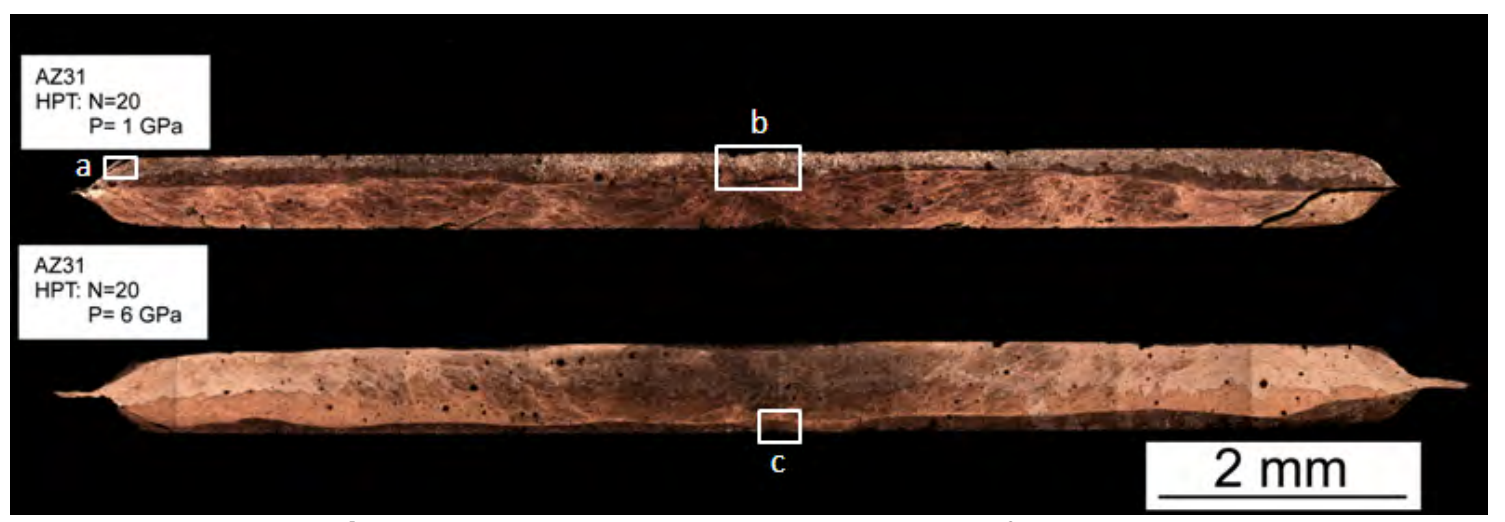

Figure 2: AZ31 magnesium discs with specific regions.

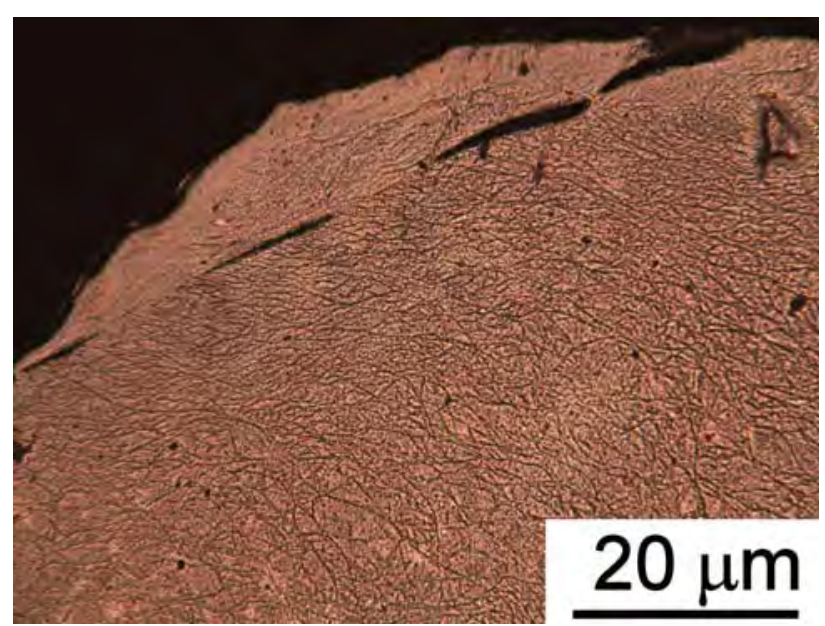

Figure 3 - Top left corner of the longitudinal section of the sample processed to 20 turns of HPT using a pressure of $1 \mathrm{GPa}$.

Figure 4 shows an area near the center at the top of the disc processed at a pressure of $1 \mathrm{GPa}$. This area is highlighted in box (b) in Figure 2. There is a long line extending through hundreds of microns parallel to the top surface of the disc. There is a clear separation between the top and the bottom on opposite sides of this line which suggests a crack dividing the sample parallel to the top surface.

Figure 5 shows an area at the center, near the bottom, of the disc processed to 20 turns of HPT using a pressure of $6 \mathrm{GPa}$. This area is highlighted in box (c) in Figure 2. Two distinct regions are observed. The division between these areas is clearly defined by a line extending parallel to the sample bottom surface.

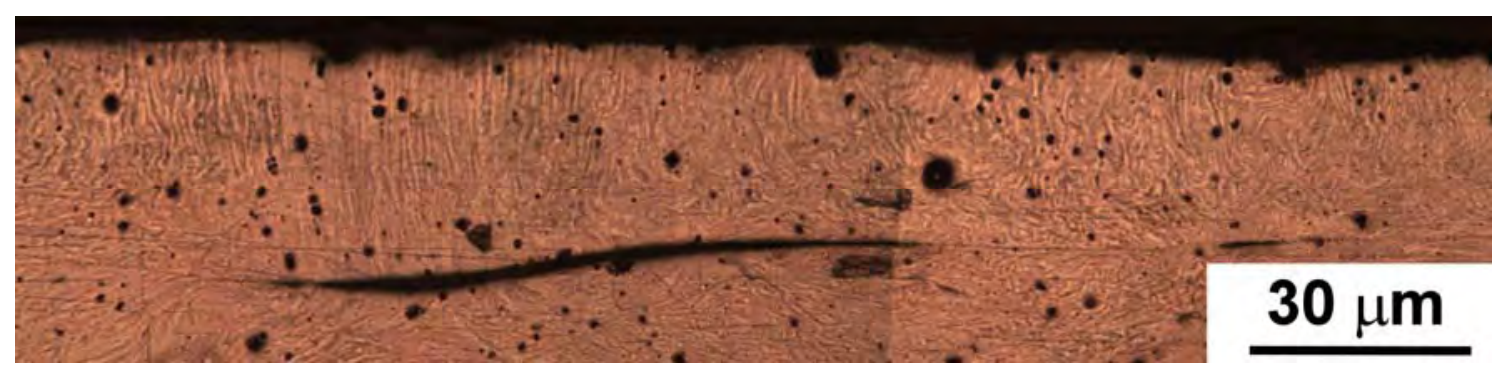

Figure 4 - Top center of the longitudinal section of the sample processed to 20 turns of HPT using a pressure of $1 \mathrm{GPa}$. 


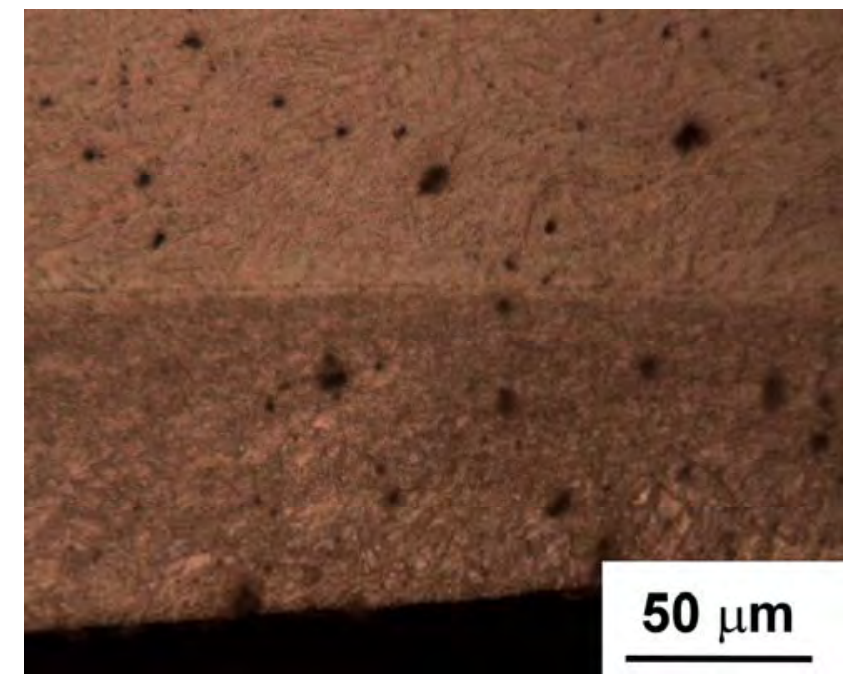

Figure 5 - Bottom center of the longitudinal section of the sample processed to 20 turns of HPT using a pressure of $6 \mathrm{GPa}$.

Figure 6 shows color-coded maps of hardness distribution along the sample longitudinal plane. The axes of the graphs indicate the distance from the center and the distance from the bottom and the color indicates the hardness level at each position. The coordinate point $(0 ; 0)$ indicates the bottom at the center of the disc. The top plot shows the distribution of hardness in the sample processed by HPT at $1 \mathrm{GPa}$ and the bottom plot shows the distribution in the sample processed at $6 \mathrm{GPa}$. There is observed a tendency for slightly higher values of hardness away from the center of the disc, near the edge. This trend is in agreement with the distribution of strain which is expected to be higher near the edge. Also it is observed that the hardness varies significantly along the through-thickness direction. This variation is clearly observed in the sample processed at $1 \mathrm{GPa}$ where the hardness near the top of the disc lies in the range of $90-110 \mathrm{Hv}$ while the hardness near the bottom lies in the range $110-130 \mathrm{Hv}$. A variation in hardness at different distances from the bottom is also present in the disc processed at $6 \mathrm{GPa}$ where a hardness of $\sim 110 \mathrm{Hv}$ is observed neat the bottom at a radial position of $\sim 3.0 \mathrm{~mm}$ and this increases to $\sim 125$ Hv near the top.

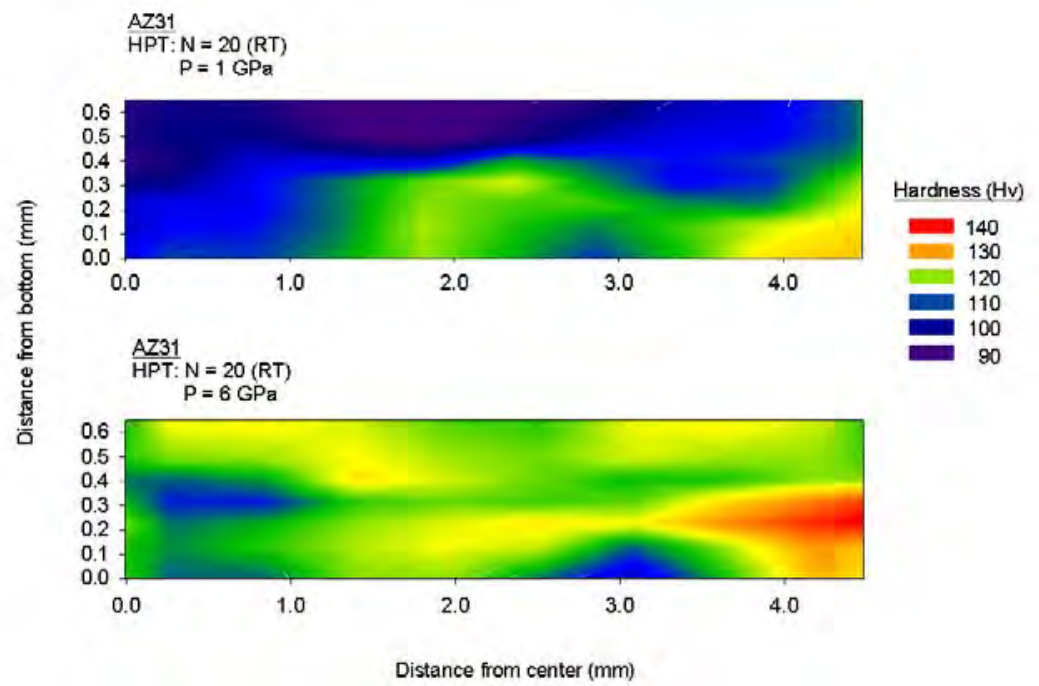

Figure 6 - Microhardness distribution along the longitudinal plane of discs of a magnesium alloy processed by HPT to 20 turns at pressures of $1 \mathrm{GPa}$ (top) and $6 \mathrm{GPa}$ (bottom). 
Figure 7 shows the hardness plotted as a function of the equivalent strain at different positions in the discs processed by HPT at a pressure of $6 \mathrm{GPa}$ for different numbers of turns. The hardness of the unprocessed material is also shown, at a strain of 0 . It is observed that the hardness increases significantly in the early stage of deformation, up to 1 turn. However, the samples processed to 5 and 20 turns show only minor variations in hardness which suggests a saturation in hardening of the material.

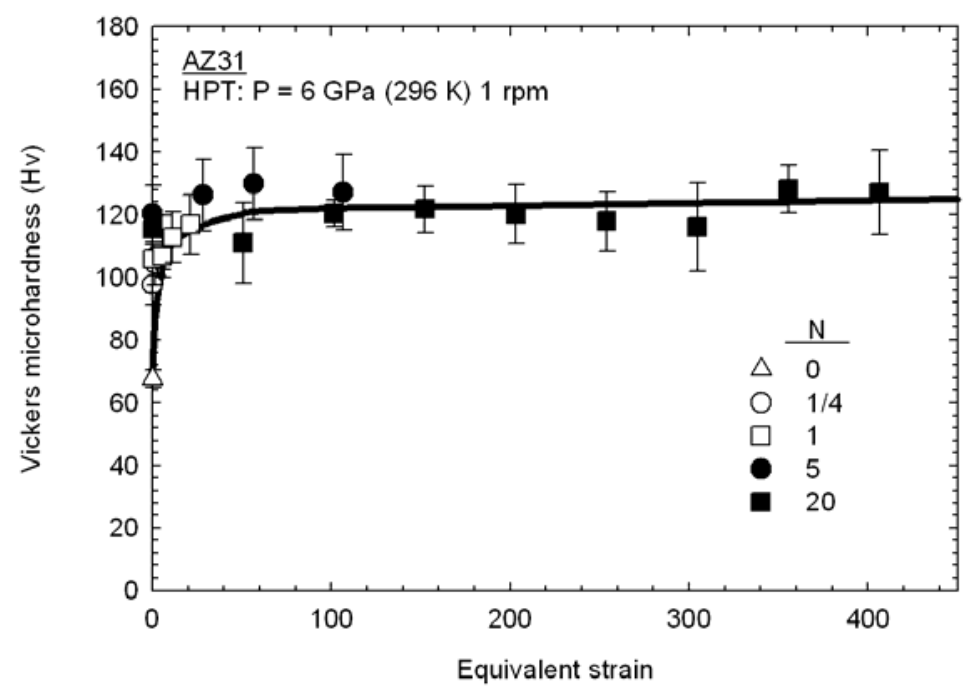

Figure 7 - Evolution of microhardness as a function of the equivalent strain for a magnesium alloy processed by HPT at a pressure of $6 \mathrm{GPa}$ for different numbers of turns.

\section{DISCUSSION}

The present results show evidence of cracking of the sample processed by HPT for 20 turns at a pressure of $1 \mathrm{GPa}$. There are two regions where cracks are observed; at the top corner of the longitudinal section of the disc and a long crack parallel to the upper surface. The former is similar to a crack observed in a similar alloy ${ }^{(1)}$ and is attributed to the friction between the sample and the lateral wall of the depression in the anvil in HPT. This friction is expected to produce a "dead-zone" in HPT and segmentation might be observed after large numbers of rotations.

The other region where cracking was observed is along a line parallel to the sample surface. This orientation suggests cracking was caused by shear deformation. The plane of maximum shear in HPT is the plane perpendicular to the axial direction. A crack perpendicular to the torsion axis is a characteristic failure mode of ductile materials in conventional torsion tests. Therefore the present results suggest the pressure of $1 \mathrm{GPa}$ is not sufficient to prevent cracking of the magnesium alloy and it leads to a behavior similar to conventional torsion testing.

The structure features observed in the longtitudinal section of the discs processed by 20 turns of HPT suggest inhomogeneity of deformation at different distances from the bottom surface. Etching is used to differentiate areas with different levels of structure defects. It is shown that the center of the disc processed at a pressure of $6 \mathrm{GPa}$ exhibits different etching behavior than the remaining disc. This is expected since the distribution of torsion deformation varies with the distance from the center. However, different etching behavior was also observed at different distances from the bottom surfaces. Variations in the plastic deformation are not expected in the through- 
thickness direction. Therefore the present results show evidence of an unpredicted inhomogeneity of deformation.

Moreover, the distribution of hardness along the longitudinal section shows evidence of inhomogeneous mechanical strength along the through-thickness direction. This supports the evidence of inhomogeneous plastic deformation in this direction. A region of low hardness is observed on the top of the disc processed by 20 turns with a pressure of $1 \mathrm{GPa}$. Also, areas with different hardnesses are observed in the disc processed to 20 turns at higher pressure. This shows the inhomogeneous deformation is not suppressed by increasing the pressure although there is a general trend of decreasing inhomogeneity.

Recent papers have also shown evidence of inhomogeneous deformation along the through-thickness direction. It has been shown that higher hardnesses are observed near the mid-plane, at equal distance from the top and bottom surfaces, in discs of iron processed by HPT and the difference in hardness increases with increasing the thickness to diameter ratio of the sample. ${ }^{(8)}$ There are also reports of significant inhomogeneity in structure and hardness distribution in a sample of aluminum with high thickness-to-diameter ratio processed by HPT. ${ }^{(12)}$ A recent paper has reported inhomogeneous structure and hardness distribution in samples of a magnesium alloy processed by HPT to lower numbers of turns. ${ }^{(10)}$ The present results show this inhomogeneity persists at large number of rotations as well.

Finally, some materials exhibit strain-hardening behavior at low deformation but there is a tendency for saturation in strengthening at large deformation. This saturation is expected since recovery increases with increasing defect density until the material rate of generation of defects during plastic deformation is similar to the rate of recovery. The present results show this saturation occurs at strains larger than $\sim 50$ in the AZ31 alloy.

\section{CONCLUSIONS}

- An AZ31 magnesium alloy was processed by HPT up to 20 turns using pressures of $1 \mathrm{GPa}$ and $6 \mathrm{GPa}$. The structure and hardness distributions on the longitudinal plane were evaluated.

- The results show evidence of cracking on the corner and parallel to the disc surface in the sample processed at $1 \mathrm{GPa}$ which shows this applied pressure is not sufficient to process this magnesium alloy.

- The structure exhibits inhomogeneous features even after 20 turns of HPT. The microhardness distribution confirms this inhomogeneity which suggests inhomogeneous deformation is not a transient effect in magnesium alloys.

\section{Acknowledgements}

The authors acknowledge the support from CAPES under Grant Agreement No. PVE 037/2012, CNPq under Grant No. 483077/2011-9 and the European Research Council under ERC Grant Agreement No. 267464-SPDMETALS.

\section{REFERENCES}

1 VALIEV, R. Z.; ISLANGALIEV, R. K.; ALEXANDROV, I V. Bulk nanostructurd materials from severe plastic deformation. Progress in Materials Science, v.45, n.2, p. 103-89. 2000. 
2 VALIEV R. Z.; LANGDON T. G. Principles of equal-channel angular pressing as a processing tool for grain refinement. Progress in Materials Science, v.51, p. 881-981. 2006.

3 ZHILYAEV A. P.; LANGDON T. G. Using high-pressure torsion for metal processeing: Fundamentals and applications. Progress in Materials Science, v.53, p. 893-979. 2008.

4 FIGUEIREDO R. B. et al. Three dimensional analysis of plastic flow during high-pressure torsion. J. Mater. Sci. In Press

5 VALIEV R. Z. et al. Structure and Deformation Behaviour of Armco Iron Subjected to Severe Plastic Deformation. Acta Materialia, v.44, p.4705-12. 1996.

6 KAWASAK M. et al. The development of hardness homogeneity in pure aluminum and aluminum alloy disks processed by high-pressure torsion. Materials Science and Engineering A, v.529, p. 345-351. 2011.

7 EDALATI K.; FUJIOKA T.; HORITA Z. Microstructure and mechanical properties of pure $\mathrm{Cu}$ procesed by high-pressure torsion. Materials Science and Engineering A, v. 497, p.168-73. 2008.

8 HOHENWARTER A. et al. Technical parameters affecting grain refinement by high pressure torsion. International Journal of Materials Research, v. 100, p. 1653-61. 2009.

9 HARA Y. et al. Microstructural and mechanical characteristics of AZ61 magnesium alloy processed by High-Pressure Torsion. Materials Transactions, v. 49, n. 1, p. 76-83. 2008.

10 FIGUEIREDO R. B. et al. Deformation heterogeneity on the cross-sectional planes of a magnesium alloy processed by high-pressure torsion. Metallurgical and Materials Transactions, v. 42A, p. 3013, 2011.

11 LEE D. J. et al. The dead metal zone in high-pressure torsion. Scripta Materialia, v.67, p.384-87. 2012.

12 SAKAI G. et al. Developing high-pressure torsion for use with bulk samples. Materials Science and Engineering A, v.406, p. 268-73. 2005. 